\title{
Comparison of hydrolytic resistance of polyurethanes and poly(urethane- methacrylate) copolymers in terms of their use as polymer coatings in contact with the physiological liquid
}

\author{
Piotr Król $^{1 *}$, Paweł Chmielarz ${ }^{1}$, Bożena Król ${ }^{1}$, Kinga Pielichowska ${ }^{2}$ \\ ${ }^{1}$ Rzeszów University of Technology, Department of Polymer Science, Faculty of Chemistry, al. Powstańców Warszawy 6, \\ 35-959 Rzeszów, Poland \\ ${ }^{2}$ AGH University of Science and Technology, Department of Biomaterials, Faculty of Materials Science and Ceramics, \\ al. Mickiewicza 30, 30-059 Kraków, Poland \\ "Corresponding authors: e-mail: pkrol@prz.edu.pl
}

\begin{abstract}
PU elastomers were synthesized using MDI, PTMO, butane-1,4-diol or 2,2,3,3-tetrafluorobutane-1,4-diol. Using the same diisocyanate and polyether reagents urethane segments were prepared, to be inserted in the poly(urethane-methacrylate) copolymers. Bromourethane or tetraphenylethane-urethane macroinitiators were used as transitional products reacting with MMA according to the ARGET ATRP. $1 \mathrm{H}$ and 13C NMR spectral methods, as well as DSC and TGA thermal methods, were employed to confirm chemical structures of synthesised elastomers and copolymers. To investigate the possibility of using synthesized polymers as biomaterials a research on keeping them in physiological liquid at $37^{\circ} \mathrm{C}$ was performed. A loss in weight and ability to sorption of water was determined and by using GPC the molecular weight changes were compared. Additionally, changes in the thermal properties of the samples after exposure in physiological liquid were documented using both the TGA and DSC methods. The studies of surface properties (confocal microscopy and SFE) of the obtained polymers were performed. The structure of the polymer chains was defined by NMR. Possible reasons of hydrolysis were discussed, stating that new copolymers are more resistant and polar biomaterials can be less interesting than elastomers.
\end{abstract}

Keywords: coatings, polyurethane elastomers, poly(urethane-methacrylate) block copolymers, ARGET ATRP, biomaterials, hydrolytic resistance.

\section{INTRODUCTION}

Today there is no doubt that the structure of segmented polyurethanes (PU) with its attendant strong polar interactions, dispersion interactions strengthened with the presence of a network of hydrogen bonds formed within the flexible and rigid segments, particularly between these segments is favorable for creating the phases of varying degrees of structured ${ }^{1}$. It turns out that this order is critical for a number of physicochemical, mechanical and biological properties, important for the application of these polymers in various fields of technology and medicin $e^{2-4}$. Meanwhile, in the present investigation, we focused on the synthesis of PU elastomer coatings with increased hydrophobicity. Also it is possible to consider applying of this type of coatings as special protective coatings to polar materials for example, old prints, wood, ceramics as well as biomaterials. Therefore, influences among the functional groups of polyurethane and the coating material are contributing to a significant increase of the adhesion, which as a result creates possibilities to obtain the tight adjoining, protecting the surface. In the latter case it is significant for obtaining durable polyurethane elastomers, also characterized by high resistance to biodegradation in conditions of their long contact with physiological liquids and tissues of living organisms. For a long time a series of commercially available polyurethane biomaterials has been known $^{5-8}$. Also a lot of methods of the structural PU modification were developed aiming at, e.g. changes of their features generally hydrophilic to more hydrophobic by introducing apolar segments of siloxane or fluoroether ${ }^{9-11}$. This is the road that leads to significant changes in both the internal structure of the PU elastomer and hydrophobi- zation of its surface ${ }^{12}$. Given the noted in recent years, significant progress in the use of new methods of atom transfer radical polymerization (ATRP), the use of some of them in obtaining urethane-acrylic copolymers synthesized in the restricted grade through an incorporation of unsaturated segments capable of radical crosslinking e.g. terminated polybutadiene polyols or low molecular weight isocyanate prepolymers extenders such as e.g. hydroxyethyl acrylate seems promising ${ }^{13}$.

Realizing this concept we synthesized new types of poly(urethane-methacrylate) copolymers, using the specially made urethane macroinitiators: bromine and tetraphenylethane, capable of reacting with methacrylate monomers ${ }^{14}$. Polyurethane structures affect the improvement in mechanical properties of that kind of copolymers, while segments of poly(methyl methacrylate) (PMMA) are used to hydrophobization of PU surface, which result from the presence of apolar methyl groups in PMMA chain. Similarly to PU elastomers also poly(urethane-acrylate) copolymers are finding application as biomaterials, among others biocompatible implant in tissue engineering ${ }^{15}$, hydrophobic antimicrobial coating ${ }^{16}$ and drug delivery in the form of appropriately formed micellar structures ${ }^{17}$. An effective control above the length of the block, which can be achieved using the methods of controlled radical polymerization (CRP), is of key importance ${ }^{14,18}$.

However, as part of the presented work we carried out the comparative study of these materials in terms of their resistance to hydrolytic degradation in the environment of physiological liquid similar to the blood plasma, similarly as described in works ${ }^{\mathbf{1 9}-21}$.

As reference material we used the synthesized by us PU elastomers, prepared by classical prepolymer me- 
thod, of the same as the above copolymers diisocyanate (MDI) and polyol (PTMO), which were extended by butane-1,4-diol, or it's fluorinated analogue 2,2,3,3-tetrafluorobutane-1,4-diol. Therefore, the primary objective of this study was to verify whether, and if so, to what extent the newly synthesized poly(urethane-methacrylate) copolymers with increased hydrophobicity are resistant to hydrolytic degradation as compared to conventional PU elastomers including their fluorinated analogues synthesized with MDI, PTMO and butane-1,4-diol or 2,2,3,3-tetrafluorobutane-1,4-diol.

\section{EXPERIMENTAL}

\section{Material}

4,4'-Methylene diphenyl diisocyanate (MDI), dibutyltin dilaurate (DBTDL), $\alpha$-bromoisobutyryl bromide (BB; $98 \%)$, ethylene glycol $(99.9 \%)$ and copper(0) metal turnings ( $\geq 99 \%$ ) were used as received from Sigma-Aldrich Inc., St. Louis, USA. Polyoxytetramethylene glycol of molecular weight 1000 (PTMO; Merck, Darmstadt, Germany) was purified by heating at $105^{\circ} \mathrm{C}$ under vacuum for $3 \mathrm{~h}$ before use. Benzophenone (99\%; ABCR $\mathrm{GmbH}$, Karlsruhe, Germany), methyl methacrylate (MMA; 99\%; Sigma-Aldrich, USA), $\mathrm{CuCl}_{2}$ (97\%; Sigma-Aldrich, USA) and PMDETA ( $\geq 98 \%$; Merck, Germany) were used without further purification. Butane-1,4-diol (BD), 2,2,3,3-tetrafluorobutane-1,4-diol (TFBD) were used as received from Sigma-Aldrich Inc., St. Louis,

\section{Synthesis methods}

PU elastomers were synthesized in a two-step polyaddition process. The first stage includes synthesis of urethane-isocyanate prepolymer terminated by -NCO groups from diisocyanate (MDI) and polyol (PTMO 1000), in the presence of $\mathrm{MEK}$. The reaction was conducted at $40^{\circ} \mathrm{C}$ for $1 \mathrm{~h}$, followed by $2 \mathrm{~h}$ at $65^{\circ} \mathrm{C}$, in order to bring the content of the unreacted - $\mathrm{NCO}$ groups in the reaction mixture to half of their initial values. This process can be approximately illustrated by the following reaction:

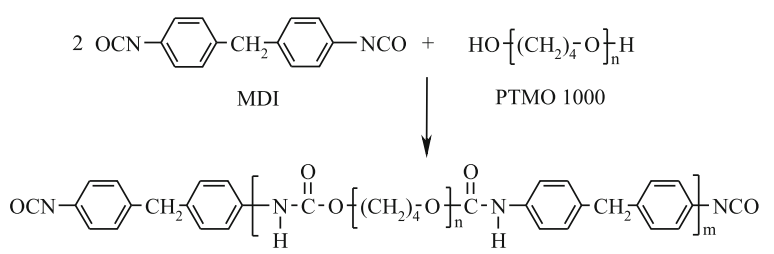

where: $n=13-14, m=5-6$.

In scheme (1) a secondary reaction of the allophanate formation reaction was omitted, which occurred under these conditions to a very small extent. The second stage involved in the chain extension of the created prepolymer by using TFBD or BD, also in MEK solution having a concentration of about $50 \mathrm{wt} \%$, and at the molar ratio of $-\mathrm{NCO}$ to $-\mathrm{OH}$ groups of $1: 1$. The DBTDL was added as the catalyst at the level of $0.1 \mathrm{wt} \%$, in relation to the PTMO. The extension reaction was carried out at $65^{\circ} \mathrm{C}$ until a complete reaction of the free $-\mathrm{NCO}$ groups (over $2 \mathrm{~h}$ ). The extension of the prepolymer can be approximately illustrated by the following reaction:

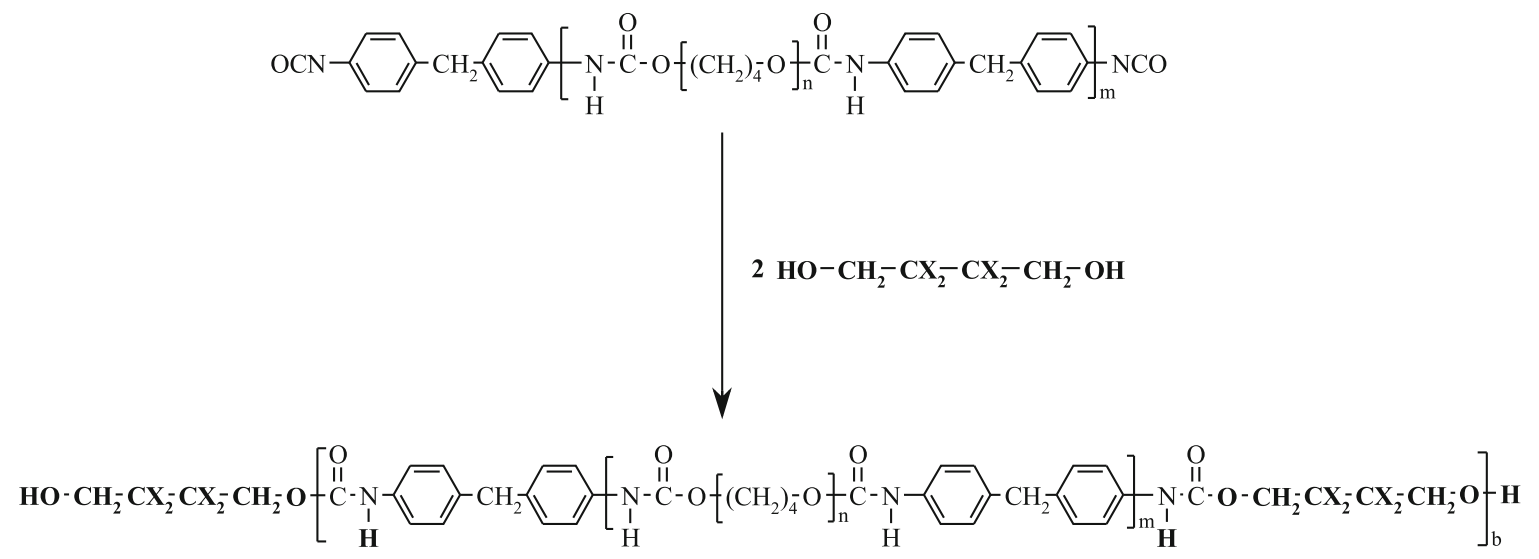

USA. Tetraphenylethane-1,2-diol (TPED) was prepared from benzophenone and 2-propanol as reported in the literature 22. 2-Hydroxyethyl-2'-methyl-2'-bromopropionate (HMB) was prepared from ethylene glycol and $\alpha$-bromoisobutyryl bromide as reported in the literature ${ }^{\mathbf{1 4}}$. Acetonitrile (99.5\%), methanol (99.9\%), acetone (99.5\%) and 2-propanol (99\%) were obtained from Chempur, Piekary Śląskie, Poland. Analytical grade N,N-dimethylformamide (DMF; Sigma-Aldrich, USA) and methyl ethyl ketone (MEK; Sigma-Aldrich, USA), were distilled and the middle portions were used after storing over type $4 \AA$ molecular sieves. Analytical reagents: Dibutylamine (Sigma-Aldrich), chlorobenzene, distilled and dried by type $4 \AA$ molecular sieves (Chempur), $\mathrm{HCl} 0,1 \mathrm{n}$ (POCH), diiodomethane, formamide (Sigma-Aldrich), physiologic salt solution (Baxter). where: $\mathrm{X}$ denotes $\mathrm{H}$ in the case of $\mathrm{BD}(b=5)$ or $\mathrm{F}$ in case of TFBD $(b=1-2)$.

In practice this reaction is more complex and it constitutes the arrangement of the following reactions of urethane-isocyanate oligomers with BD or TFBD substrate, or with transitional products of the type of urethane oligomers terminated with $-\mathrm{OH}$ groups ${ }^{23}$. The task of DBTDL catalyst, was to accelerate reactions occurring in subsequent steps, leading to the PU, about the more great molecular weight. The resulting PU process solutions in MEK were poured onto poly(tetrafluoroethylene) plates, with the help of the applicator with a slot width of $1 \mathrm{~mm}$, thus forming the membrane which was dried in a vacuum oven at $80^{\circ} \mathrm{C}$ for $6 \mathrm{~h}$. The resulting films were then subjected to seasoning under room temperature for 10 days, and then removed without distortion from poly(tetrafluoroethylene) plates, yielding PU films used for the test. 
Poly(urethane-methacrylate) copolymers were synthesized in a three-step process, consisting of a two-stage polyaddition and controlled radical reaction of connecting acrylic segments.

The first stage includes a synthesis of prepolymer from MDI and PTMO, carried out in a manner similar to the case of the PU elastomers. In the second stage at $65^{\circ} \mathrm{C}$ the resulting prepolymer is reacted with TPED or $\mathrm{HMB}$, at the equimolar ratio of $-\mathrm{NCO}$ to $-\mathrm{OH}$ groups using DBTDL as a catalyst, getting macroinitiators in MEK solution, appropriately urethane-tetraphenylethane (TPE-PU-TPE) or bromourethane (MBP-PU-MBP) containing $0 \mathrm{wt} \%$ content of $-\mathrm{NCO}$ groups ${ }^{14}$. The TPE-PU-TPE macroinitiator synthesis process is presented by the following scheme:

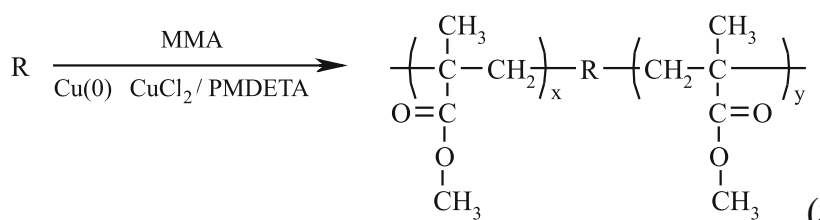

where: $\mathrm{R}$ denotes part of the structure coming from TPE-PU-TPE or MBP-PU-MBP.

The resulting copolymer deposites were precipitated from the reaction mixture with methanol, and then washed with acetonitrile to remove from them a possible content of PMMA homopolymer.

The resulting copolymers were dried in a vacuum oven at $80^{\circ} \mathrm{C}$ for $6 \mathrm{~h}$, then dissolved in acetone and as $50 \mathrm{wt} \%$ solutions were distributed on the surface of<smiles>CCOC(=O)C(=O)NC(=O)Nc1ccc(Cc2ccc([N+](=O)[O-])cc2)cc1</smiles>

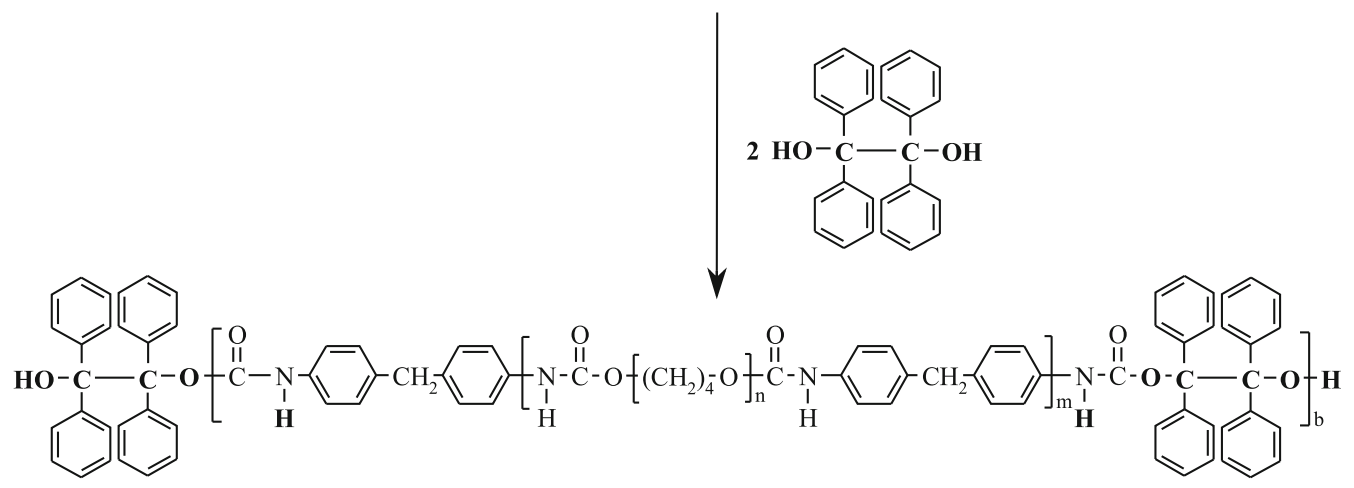

where: $b=2$.

Meanwhile, the MBP-PU-MBP macroinitiator synthesis process is presented by the scheme:<smiles>CCOC(=O)C(=O)Nc1ccc(Cc2ccc([N+](=O)[O-])cc2)cc1</smiles>

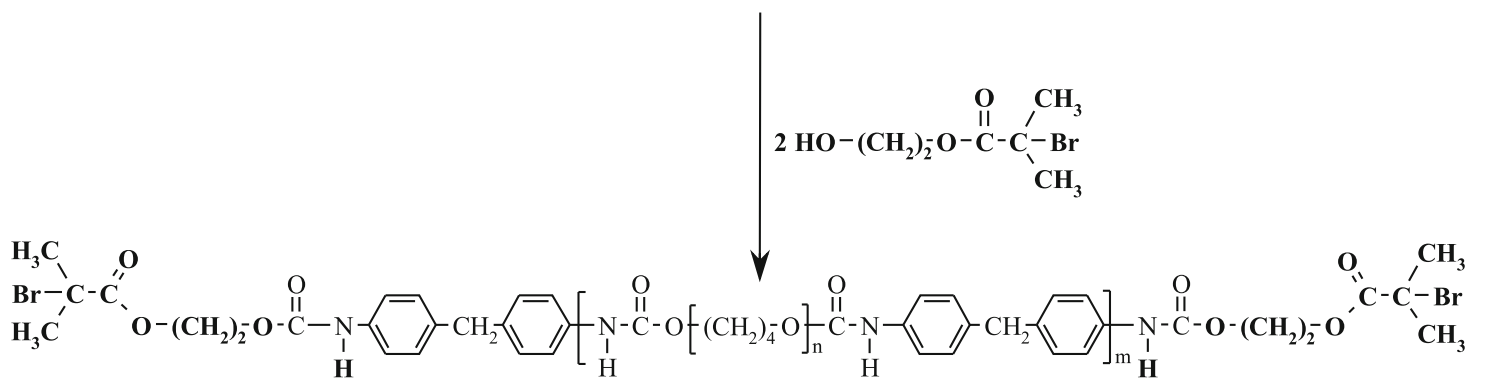

The third stage included a $30 \mathrm{~h}$ synthesis of tri-block copolymers by using ARGET ATRP method, in the presence of limited amount of air and with a very small (370 ppm) amount of copper catalyst. In this case, substrates were previously received TPE-PU-TPE and MBP-PU-MBP macroinitiators, as well as MMA. The reactions were carried out in the presence of a reducing metal $\mathrm{Cu}(0)$ and the $\mathrm{CuCl}_{2} / \mathrm{PMDETA}$ catalyst complex in DMF environment ${ }^{14}$. In the case of the TPE-PU-TPE macroinitiator the reaction from MMA was performed at $80^{\circ} \mathrm{C}$ (reported now for the first time), while the MBPPU-MBP macroinitiator at $100^{\circ} \mathrm{C}$. The scheme below presents the polymerization process: poly(tetrafluoroethylene) plates, and then dried in a vacuum oven at $80^{\circ} \mathrm{C}$ for $6 \mathrm{~h}$. The resulting films were then subjected to seasoning under room temperature for 10 days, and then removed without distortion from poly(tetrafluoroethylene) plates, yielding copolymer films used for the test.

Chemical compositions of prepared elastomer and copolymer samples in the form of thin films are presented in Table 1.

\section{Hydrolytic degradation study}

Samples of the obtained polymers were subjected to hydrolytic degradation test at $37^{\circ} \mathrm{C}$ in an incubator for a period of 8 weeks in an environment similar to the physiological fluid of the blood plasma ${ }^{20}$. The loss in 
Table 1. The chemical composition of synthesized polyurethane elastomers and poly(urethane-methacrylate) copolymers based MDI diisocyanate and PTMO polyol

\begin{tabular}{|c|c|c|c|c|c|c|c|c|c|c|c|c|c|c|c|c|c|c|c|}
\hline \multirow{3}{*}{$\begin{array}{l}\text { Sample } \\
\text { No. }\end{array}$} & \multirow{3}{*}{$\begin{array}{l}\text { Type of } \\
\text { polymer }\end{array}$} & \multirow{3}{*}{$\begin{array}{l}\text { Type of } \\
\text { diol }\end{array}$} & \multirow{3}{*}{ Monomer } & \multicolumn{6}{|c|}{ Characteristic of molecular weights } & \multicolumn{6}{|c|}{$\begin{array}{c}\text { Surface free energy parameters } \\
{\left[\mathrm{mJ} / \mathrm{m}^{2}\right]} \\
\text { standard deviation }\end{array}$} & \multicolumn{4}{|c|}{$\begin{array}{l}\text { Surface roughnes grade parameters } \\
\qquad[\mu \mathrm{m}]\end{array}$} \\
\hline & & & & \multicolumn{3}{|c|}{ before exposure } & \multicolumn{3}{|c|}{ after exposure } & \multicolumn{3}{|c|}{ before exposure } & \multicolumn{3}{|c|}{ after exposure } & \multicolumn{2}{|c|}{$\begin{array}{c}\text { before } \\
\text { exposure }\end{array}$} & \multicolumn{2}{|c|}{$\begin{array}{c}\text { after } \\
\text { exposure }\end{array}$} \\
\hline & & & & $M_{n}$ & $M_{w}$ & $\begin{array}{c}M_{w} / M \\
n\end{array}$ & $M_{n}$ & $M_{w}$ & $\begin{array}{c}M_{w} / M \\
n\end{array}$ & $\gamma s$ & $\gamma s^{d}$ & $\gamma s^{p}$ & $\gamma s$ & $\gamma s^{d}$ & $\gamma s^{p}$ & $R_{a}$ & $R_{z}$ & $R_{a}$ & $R_{\mathrm{z}}$ \\
\hline PU-1-E & $\begin{array}{c}\mathrm{PU} \\
\text { elastomer }\end{array}$ & $\mathrm{BD}$ & - & 36100 & 46200 & 1.280 & 32320 & 49000 & 1.516 & $\begin{array}{c}43.08 \\
0.09 \\
\end{array}$ & $\begin{array}{c}39.50 \\
0.09 \\
\end{array}$ & $\begin{array}{l}3.58 \\
0.01 \\
\end{array}$ & $\begin{array}{c}45.19 \\
0.10 \\
\end{array}$ & $\begin{array}{c}40.46 \\
0.10 \\
\end{array}$ & $\begin{array}{l}4.73 \\
0.01 \\
\end{array}$ & 0.023 & 0.037 & 0.142 & 0.247 \\
\hline PU-2-E & $\begin{array}{c}\text { PUF } \\
\text { elastomer }\end{array}$ & TFBD & - & 11900 & 17600 & 1.479 & 11900 & 17700 & 1.487 & $\begin{array}{c}28.31 \\
0.08\end{array}$ & $\begin{array}{c}25.54 \\
0.08\end{array}$ & $\begin{array}{l}2.77 \\
0.01\end{array}$ & $\begin{array}{c}29.92 \\
0.04\end{array}$ & $\begin{array}{r}26.87 \\
0.04\end{array}$ & $\begin{array}{l}3.05 \\
0.01\end{array}$ & 0.032 & 0.033 & 0.213 & 0.241 \\
\hline PU-3-K & $\begin{array}{c}\text { poly } \\
\text { (urethane- }\end{array}$ & $\begin{array}{c}\text { TPED } \\
\text { macrodiol }\end{array}$ & MMA & 23820 & 36350 & 1.526 & 23720 & 36350 & 1.532 & $\begin{array}{c}43.04 \\
0.11 \\
\end{array}$ & $\begin{array}{l}39.33 \\
0.11 \\
\end{array}$ & $\begin{array}{l}3.71 \\
0.02\end{array}$ & $\begin{array}{c}43.13 \\
0.10 \\
\end{array}$ & $\begin{array}{c}39.23 \\
0.10 \\
\end{array}$ & $\begin{array}{l}3.90 \\
0.02\end{array}$ & 0.251 & 0.252 & 1.518 & 1.521 \\
\hline PU-4-K & $\begin{array}{l}\text { metha- } \\
\text { crylate) } \\
\text { copolymer }\end{array}$ & $\begin{array}{c}\mathrm{HMB} \\
\text { macrodiol }\end{array}$ & MMA & 17400 & 38800 & 2.230 & 17350 & 38700 & 2.231 & $\begin{array}{l}42.00 \\
0.08\end{array}$ & $\begin{array}{l}40.28 \\
0.08\end{array}$ & $\begin{array}{l}1.72 \\
0.01\end{array}$ & $\begin{array}{l}42.14 \\
0.06\end{array}$ & $\begin{array}{l}40.21 \\
0.05\end{array}$ & $\begin{array}{l}1.93 \\
0.01\end{array}$ & 0.254 & 0.254 & 1.368 & 1.371 \\
\hline
\end{tabular}

weight of the samples $\Delta m / m_{o}(\%)$ was calculated using the following formula:

$\frac{\Delta m_{i}}{m_{i, 0}}=\frac{m_{i, 0}-m_{i, t}}{m_{i, 0}} \cdot 100 \%$

where $m_{i, 0} m_{i, t,}$ denotes the weight of dry sample $i$, before and after degradative incubation at time $t$.

The physical state of the surface of polymer samples before and after hydrolytic degradation was compared by using confocal microscopy with the optical 3D NanoFocus system.

\section{Water sorption study}

Water sorption $S_{i}(\%)$ was calculated according to the analogous equation (6), in which the $m_{i, t}-$ in this case is the weight of polymer sample immediately after removal from saline, after the degradative incubation at time $t$, drained in the filter paper.

\section{Characterization techniques of the polymer structures}

${ }^{1} \mathrm{H}$ and ${ }^{13} \mathrm{C}$ NMR spectra were taken with the use of the spectrometer FT-NMR Bruker Avance 500II (Bruker, Karlsruhe, Germany). The PU sample and copolymers were dissolved in DMSO- $d_{6} / h$-DMSO and the solutions with the concentration of about $0.2 \mathrm{~g} / \mathrm{dm}^{3}$ were prepared. TMS was used as a standard.

Number-average $\left(M_{\mathrm{n}}\right)$ and weight-average $\left(M_{\mathrm{w}}\right)$ molecular weights and molecular weight distribution (MWD) were determined by GPC using a Viscotek T60A system (Viscotek, Houston, USA) equipped with a triple detector: refractometric (RI), light scattering (LS) and viscosity detector (DV). Separations were made at $25 \pm 0.1^{\circ} \mathrm{C}$ on a GMHHRL column packed with TSK-gel of pore diameter $5 \mu \mathrm{m}$ Thoso-Haas, and Styragel 1 and 2 Waters. The THF flow rate was $1 \mathrm{~mL} / \mathrm{min}$. Column calibration was performed using typical polystyrene standards. The operation of the chromatograph was controlled by original computer software TRISEC Data Acquisition System by Viscotec Corporation.

\section{Confocal microscopy}

The physical state of the surface of polymer samples before and after hydrolytic degradation was compared using confocal microscopy with the optical $3 D$ NanoFocus system (Oberhausen, Germany) using the $320 \times 320 \mathrm{~mm}$ objectives and magnification 50x. The nanometer precision resolution is based on the innovative confocal Multi-Pinhole-Technology in combination with the piezo module. Light source is a high efficiency LED, $\lambda=505 \mathrm{~nm}$. Image acquisition module from NanoFocus system is a fast digital camera with progressive scan technology, up to $55 \mathrm{fps}, 512 \times 512$ Pixel, 10 bit and firewire.

With the use of the confocal microscopy the parameters of surface roughness grade of polymer coating before and after hydrolytic degradation were determined. Values of the coefficients of roughness $R_{a}$ (arithmetic mean deviation of the assessed profile) and $R_{z}$ (maximum height of the profile within a sampling length) were obtained from the $\mu$ surf Premium software.

\section{Method for determination of components of surface free energy for solids}

The physical parameters of the surface energy of a solid $\gamma_{S}$ were found on the basis of the Owens-Wendt method which assumes that the surface free energy $\gamma_{S, L}$ may be presented as a sum of two components ${ }^{24}$ :

$\gamma_{S, L}=\gamma_{S, L}^{d}+\gamma_{S, L}^{p}$

where: $\gamma_{S, L}{ }^{d}$ denotes surface energy connected with dispersion interactions and $\gamma_{S, L}{ }^{p}$ - surface energy connected with polar acid-base interactions.

Equation (7) is generally applicable both to a solid phase, and the subscript of $\mathrm{S}$ is used then, and to a wetting liquid (standard liquid or tested liquid), with the subscript of L. The surface free energy (SFE) parameters for solids $(S)$ and for liquids $(L)$ interacting with those solids should satisfy the Owens-Wendt equation:

$\gamma_{L} \cdot \frac{1+\cos \Theta}{2}=\sqrt{\gamma_{S}^{d} \cdot \gamma_{L}^{d}}+\sqrt{\gamma_{S}^{p} \cdot \gamma_{L}^{p}}$

where $\mathrm{Q}$ is the experimentally found contact angle between a liquid drop and a solid surface under investigation. So, contact angles $\Theta$ were first measured for the surfaces of cationomer coatings with the use of 2 pairs of model liquids (water-diiodomethane) with known parameters of $\gamma_{L}, \gamma_{L}{ }^{d}$ and $\gamma_{L}{ }^{p}$ (Table 2) ${ }^{25}$. Then, equation (8) was used to calculate the values of $\gamma_{S}{ }^{d}$ and $\gamma_{S}^{p}$ for the studied cationomers. The values of $\gamma_{\mathrm{S}}$ were calculated from equation (7).

The contact angles $\Theta$ were measured with the use of the method suggested by Zisman ${ }^{26}$, i.e. by means of an optical goniometer (Cobrabid Optica - Warsaw) with a digital camera installed in the axial direction of its lens.

Table 2. Surface properties of model measuring liquids ${ }^{\mathbf{2 5}}$

\begin{tabular}{|c|c|c|c|}
\hline & \multicolumn{3}{|c|}{ Surface free energy parameters } \\
\hline \multirow{2}{*}{ Model measuring liquid } & \multicolumn{3}{|c|}{$\left[\mathrm{mJ} / \mathrm{m}^{2}\right]$} \\
\hline & $\gamma_{L}$ & $\gamma_{L}{ }^{d}$ & $\gamma_{L}{ }^{p}$ \\
\hline Water & 72.8 & 21.8 & 51.0 \\
\hline Diiodomethane & 50.8 & 48.5 & 2.3 \\
\hline
\end{tabular}




\section{Thermal analysis}

Thermal gravimetric analysis of the samples of the obtained PU elastomer and poly(urethane-methacrylate) copolymer films before and after incubation was carried out using TGA/DSC1 thermobalance from Mettler Toledo. TG; $\mathrm{D} m / m=f(T)$ and DTG; $\mathrm{d} m / \mathrm{d} T=f(T)$ were derived. The measurement conditions were as follows: sample weight $\sim 1.5 \mathrm{mg}$, gas flow $-50 \mathrm{~cm}^{3} / \mathrm{min}$, aluminium pan. The measurements were taken within the temperature range of $25-550^{\circ} \mathrm{C}$, at a constant heating rate of $10 \mathrm{deg} / \mathrm{min}$, in nitrogen.

A Mettler Toledo type $822^{\mathrm{e}}$ differential calorimeter (DSC) with Star ${ }^{\mathrm{e}}$ System software was employed to analyze the thermal properties of cured samples. The samples (10-40 mg) were placed in aluminum crucibles and placed in the measuring chamber. Initially, samples of the elastomers were heated up to $220^{\circ} \mathrm{C}$ at the rate of $10^{\circ} / \mathrm{min}$ to eliminate stresses, which possibly could be left after the molding process, and then they were cooled down to $-60^{\circ} \mathrm{C}$. After another $10 \mathrm{~min}$, their progressive heating was initiated at the rate of $10 \mathrm{deg} / \mathrm{min}$. The measurements were taken within the temperature range of from -60 to $220^{\circ} \mathrm{C}$, in the environment of nitrogen, which was passed at the rate of $30 \mathrm{~cm}^{3} / \mathrm{min}$. Meanwhile, in the case of copolymers measurements were taken within the temperature range of from -90 to $150^{\circ} \mathrm{C}$.
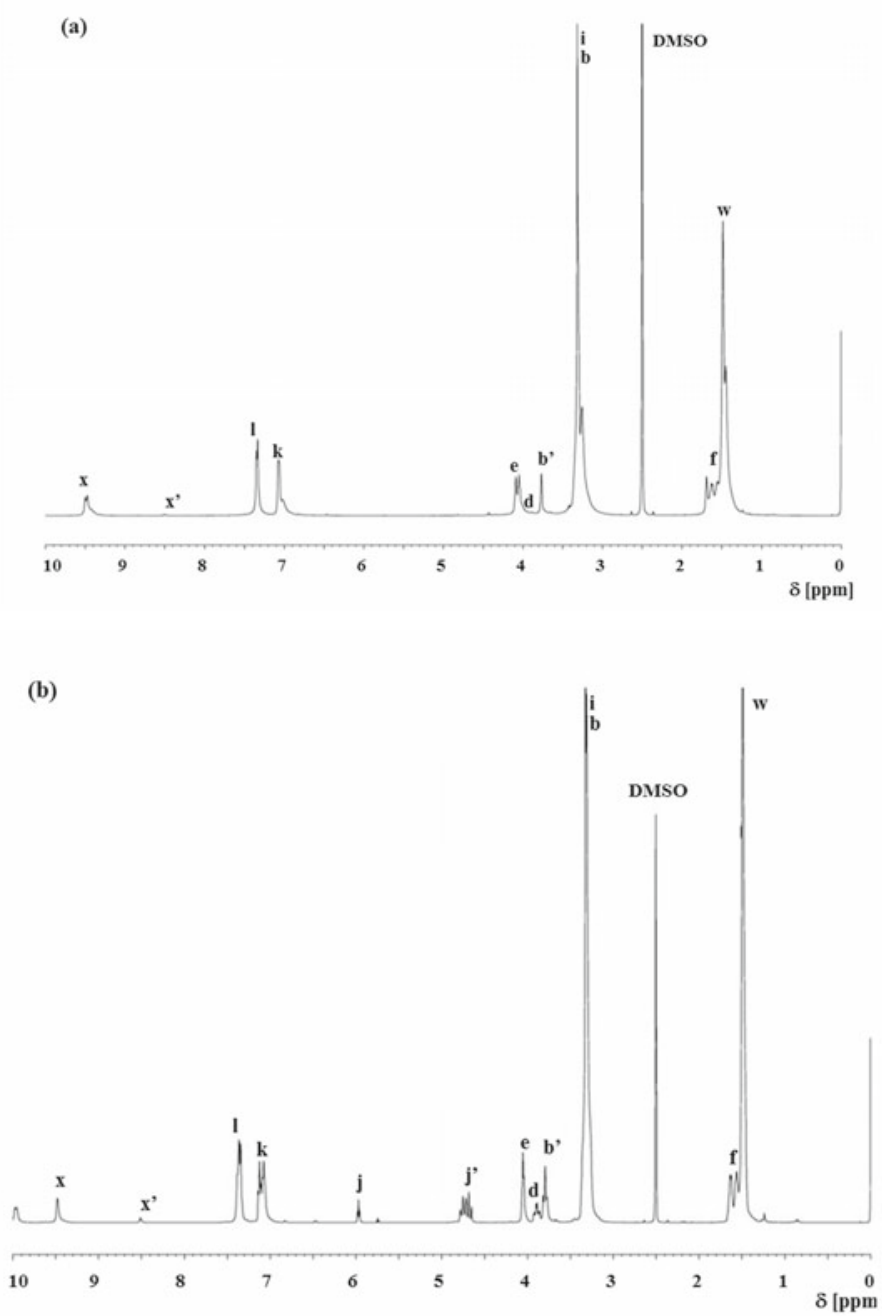

\section{RESULTS AND DISCUSSION}

The chemical structures of the synthesized polyurethane elastomers (PU-1-E and PU-2-E) and poly(urethane-methacrylate) copolymers (PU-3-K and PU-4-K) were confirmed by ${ }^{1} \mathrm{H}$ NMR (Fig. 1, Table 3 ) and ${ }^{13} \mathrm{C}$ NMR spectroscopy (Table 4). In the case of copolymer PU-3-K and PU-4-K, similar structures have been characterized respectively at work ${ }^{\mathbf{2 2}}$ and ${ }^{\mathbf{1 4}}$, but they are not the same results as the ones obtained by using other catalyst complexes.

Figure 2 shows structural fragments, which make the chains of $(a-c)$ PU-1-E elastomer, $(a, b, d)$ PU-2-E elastomer, (a, b, e) PU-3-K copolymer and (a, b, f) PU-4-K copolymer. These results of ${ }^{1} \mathrm{H}$ NMR and ${ }^{13} \mathrm{C}$ NMR spectroscopy show that PU elastomers and poly(urethane-methacrylate) copolymers were successfully synthesized.

For the initial assessment of the suitability of polyurethane as biomaterial there is an important test of resistance to hydrolytic degradation under the conditions similar to those existing in the body, or for example during the incubation in physiologic salt solution having an ionic strength similar to blood plasma. The change of mass of the test material over a longer period of time at least several weeks has been observed as the basic criterion for such resistance. The results of performed examinations are shown in Figure 3.
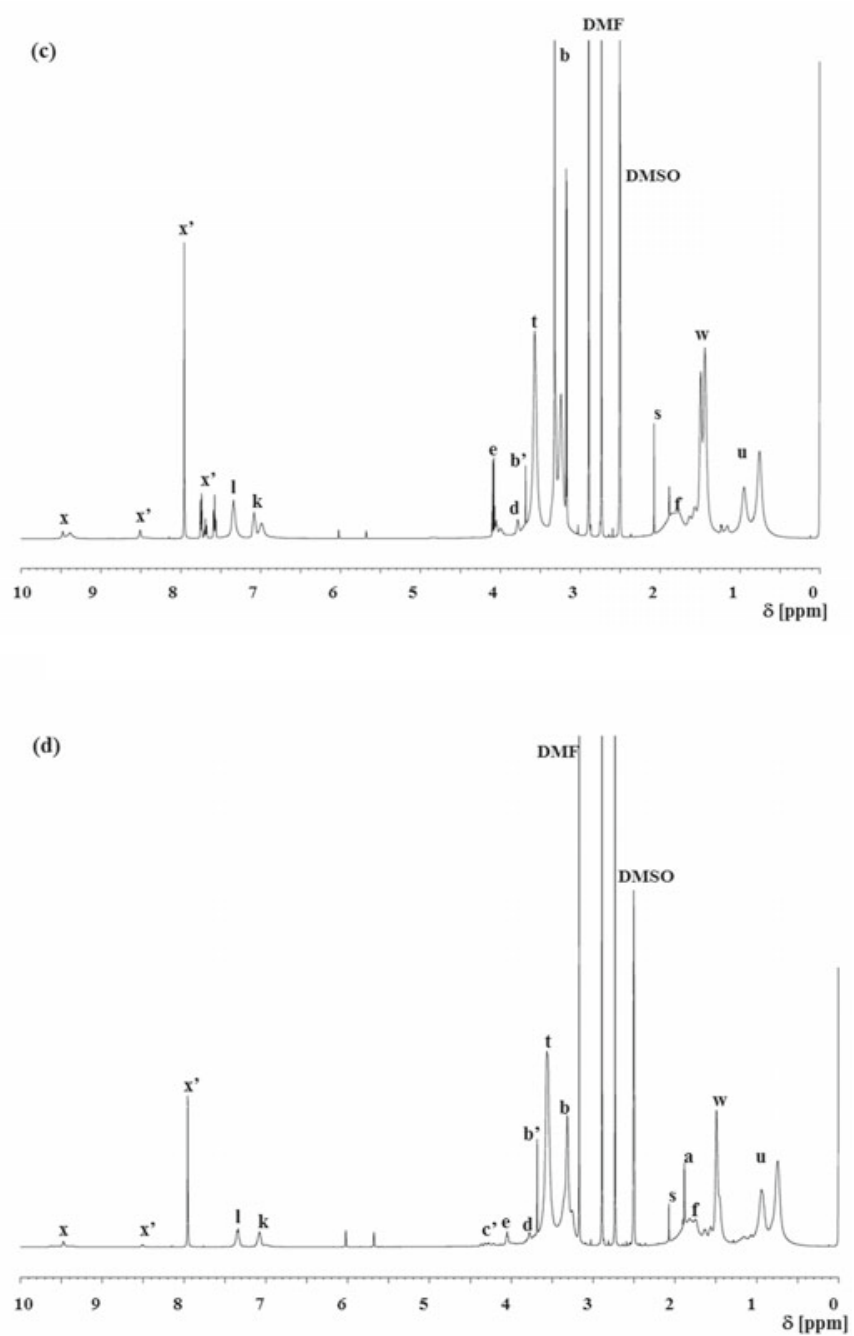

Figure 1. ${ }^{1} \mathrm{H}$ NMR spectra of (a) PU-1-E elastomer, (b) PU-2-E elastomer, (c) PU-3-K copolymer and (d) PU-4-K copolymer 
They showed that in spite of the relatively small loss in weight of less than $1 \%$, the values of the parameter synthesized PU elastomers were characterized by a significantly greater weight loss (about $1 \%$ ) than the poly(urethane-methacrylate) copolymers. If the mass loss of the PU-2-E sample obtained with TFBD is clearly smaller than the corresponding PU without fluorine, which is explained more hydrophobic of chains containing the fluorinated segments, meanwhile PU-3-K and PU-4-K copolymers exhibit a similar resistance to the hydrolytic degradation in studied conditions. The above results correspond to the results of determinations of sorption of water, which for PU is approximately $2.5 \%$ (for the fluorine-containing PU 2.05\%), and for copolymers is at a range of $0.6-0.7 \%$, which is presented in Figure 4.

The examined PU, although they are linear polymers about mainly of physical networks, resulting from the presence of hydrogen bonds, practically do not absorb water, so are strongly hydrophobic material in their mass.

Research carried out by NMR spectroscopy confirmed that the fundamental structure of these chains did not change during the incubation of samples in the physio-

Table 3. ${ }^{1} \mathrm{H}$ NMR data of polyurethane elastomers (PU-1-E and PU-2-E) and poly(urethane-methacrylate) copolymers (PU-3-K and PU-4-K)

\begin{tabular}{|c|c|c|c|c|}
\hline \multirow{2}{*}{$\begin{array}{l}\text { Type of nucleus } \\
{ }^{1} \mathrm{H} \text { by Figure } 1 .\end{array}$} & PU-1-E & PU-2-E & PU-3-K & PU-4-K \\
\hline & \multicolumn{4}{|c|}{ Chemical shift [ppm] } \\
\hline$a$ & - & - & - & $1.88-1.90$ \\
\hline$c^{\prime}$ & - & - & - & $4.32-4.37$ \\
\hline$x$ & $9.47-9.50$ & 9.48 & $9.35-9.50$ & 9.49 \\
\hline$x^{\prime}$ & 8.50 & 8.50 & $7.95-8.50$ & $8.00-8.49$ \\
\hline 1 & $7.33-7.35$ & $7.34-7.36$ & 7.34 & 7.34 \\
\hline $\mathrm{k}$ & 7.07 & $7.07-7.14$ & $6.99-7.08$ & 7.07 \\
\hline$d$ & 3.77 & $3.77-3.82$ & 3.78 & 3.77 \\
\hline $\mathrm{i}$ & 3.32 & 3.33 & - & - \\
\hline $\mathrm{b}$ & 3.32 & 3.33 & 3.32 & 3.32 \\
\hline $\mathrm{w}$ & 1.49 & 1.49 & $1.44-1.49$ & 1.49 \\
\hline $\mathrm{b}^{\prime}$ & 3,68 & 3,68 & 3.58 & 3,68 \\
\hline$f$ & $1.62-1.64$ & $1.62-1.64$ & $1.56-1.71$ & $1.57-1.64$ \\
\hline $\mathrm{e}$ & $4.05-4.09$ & $4.04-4.05$ & $4.01-4.05$ & 4.04 \\
\hline$w^{\prime}$ & 1.45 & - & - & - \\
\hline$b^{\prime \prime}$ & 3.24 & - & - & - \\
\hline j & - & $5.96-5.98$ & - & - \\
\hline j' & $\begin{array}{c}- \\
-\end{array}$ & $4.65-4.78$ & 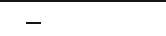 & - \\
\hline $\mathrm{t}$ & - & 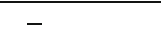 & 3.71 & 3.56 \\
\hline $\mathrm{s}$ & - & - & $2.01-2.15$ & 2.07 \\
\hline $\mathrm{u}$ & - & - & $0.75-1.26$ & $0.74-1.28$ \\
\hline
\end{tabular}

Table 4. ${ }^{13} \mathrm{C}$ NMR data of polyurethane elastomers (PU-1-E and PU-2-E) and poly(urethane-methacrylate) copolymers (PU-3-K and PU-4-K)

\begin{tabular}{|c|c|c|c|c|}
\hline \multirow{2}{*}{$\begin{array}{l}\text { Type of nucleus } \\
{ }^{13} \mathrm{C} \text { by Figure } 1 .\end{array}$} & PU-1-E & PU-2-E & PU-3-K & PU-4-K \\
\hline & \multicolumn{4}{|c|}{ Chemical shift [ppm] } \\
\hline 21 & 40.00 & 39.00 & $38.94-39.94$ & $38.93-39.93$ \\
\hline 13 & 153.46 & 153.48 & 162.10 & 162.20 \\
\hline 9 & 135.31 & 135.14 & 135.59 & 135.66 \\
\hline 10 & 118.15 & $118.51-118.19$ & $117.98-118.17$ & 118.16 \\
\hline 11 & 128.68 & $128.72-128.88$ & 128.49 & $125.65-128.73$ \\
\hline 12 & 138.92 & 137.58 & 137.56 & 137.06 \\
\hline 2 & 69.60 & 69.67 & 69.65 & 69.62 \\
\hline 4 & 25.97 & 25.99 & 25.99 & 25.99 \\
\hline 5 & 69.34 & 69.38 & 69.37 & 69.36 \\
\hline 6 & 25.45 & 25.49 & 25.48 & 25.48 \\
\hline 7 & 25.64 & 25.65 & 25.65 & 25.65 \\
\hline 8 & 63.79 & 63.81 & 63.69 & 63.81 \\
\hline 30 & 25.15 & 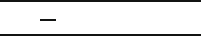 & - & - \\
\hline 31 & 63.58 & - & - & - \\
\hline 32 & $\begin{array}{ll}- \\
\end{array}$ & 69.31 & 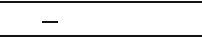 & - \\
\hline 33 & - & $58.44-59.08$ & - & - \\
\hline 34 & - & 63.80 & - & - \\
\hline 15 & - & - & 176.08 & 177.27 \\
\hline 16 & - & $\begin{array}{llll}- & \end{array}$ & 51.52 & 51.62 \\
\hline 17 & - & $\begin{array}{ll}- \\
\end{array}$ & 52.65 & 53.58 \\
\hline 18 & 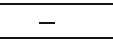 & - & 43.82 & $43.81-44.18$ \\
\hline 19 & - & - & $16.01-21.01$ & $15.89-18.51$ \\
\hline 29 & - & $\begin{array}{l}- \\
-\end{array}$ & 83.40 & - \\
\hline 28 & - & - & 129.51 & - \\
\hline 27 & 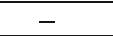 & - & 126.12 & - \\
\hline 26 & - & - & 136.93 & - \\
\hline 25 & - & - & - & 30.67 \\
\hline 24 & - & - & - & 48.50 \\
\hline 23 & - & - & - & $176.07-177.27$ \\
\hline 22 & - & - & - & 63.81 \\
\hline
\end{tabular}


(a)

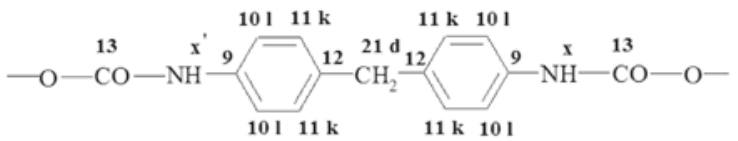

(b)

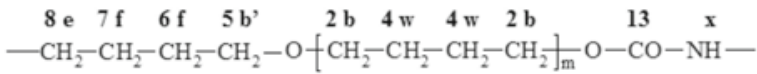

(c)

(d)

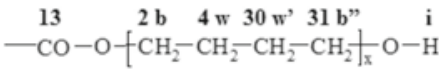

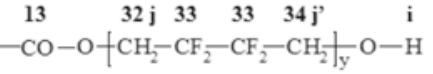

(e)

$$
\text { (19) }
$$

(f)

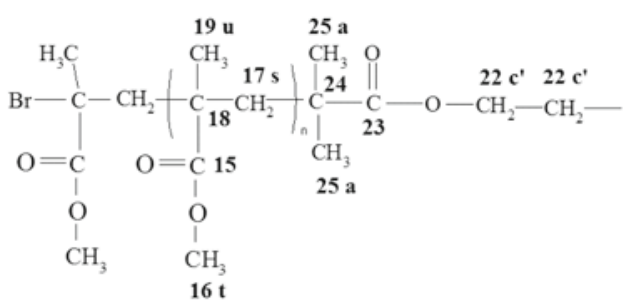

Figure 2. Chemical structure of $(\mathrm{a}-\mathrm{c})$ PU-1-E elastomer, (a, b, d) PU-2-E elastomer, (a, b, e) PU-3-K copolymer and $(\mathrm{a}, \mathrm{b}, \mathrm{f}) \mathrm{PU}-4-\mathrm{K}$ copolymer

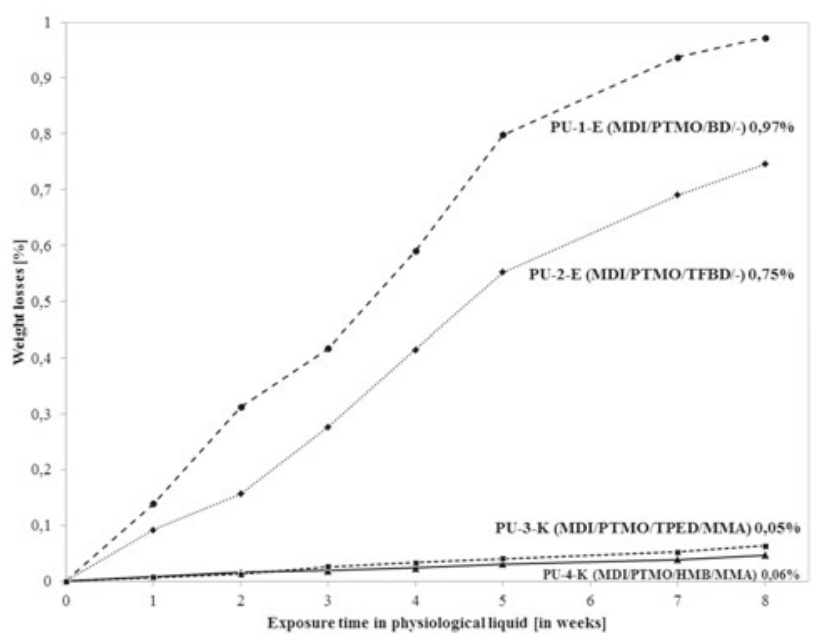

Figure 3. Relations of the weight losses [\%] from the exposure time of films of PU elastomers and poly(urethane-methacrylate) copolymers in physiological liquid

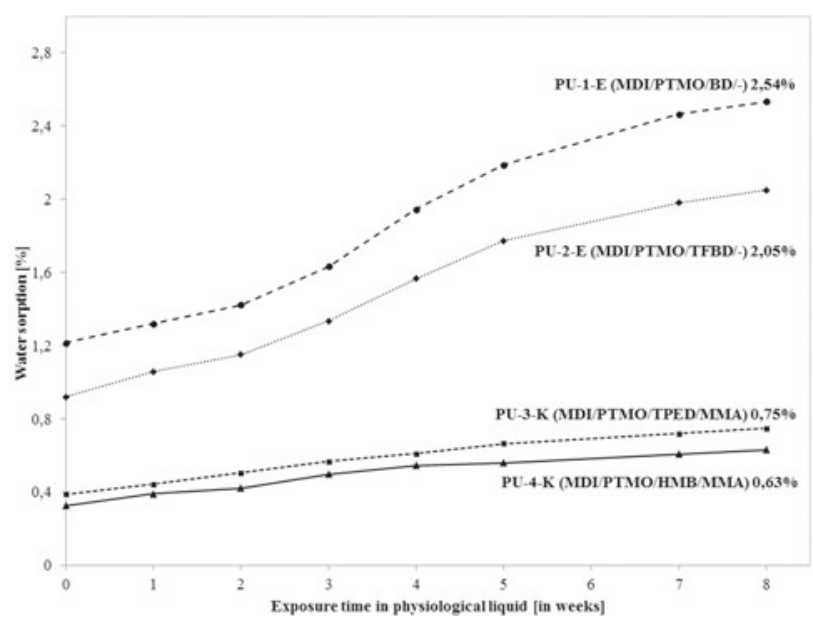

Figure 4. Relations of the water sorption [\%] from the exposure time of films of PU elastomers and poly(urethane-methacrylate) copolymers in physiological liquid

logic salt solution, but about the course of degradation - although to a limited extent - shows the character of the molecular weight distribution of studied polymers derived from GPC chromatograms. The stated lack of significant differences in the NMR spectres of samples before and after exposure in the physiologic salt solution, which suggests that any structural changes are of very subtle nature, and it can be demonstrated only in the course of further quantitative analyzes.

$M_{n}$ values and the determined degrees of polydispersity values of the studied polymers are given in Table 1. It is obvious that the applied method of the calibration of GPC columns based on polystyrene standards, isn't a reliable method for assessing the absolute values of the molecular weights of the resulting polymers, especially for poly(urethane-methacrylate) copolymers, of which fragments of chains differing in the polarity are probably in the different degree soluble in average polar eluent, which is THF. For this reason, the values of $M_{n}$ and $M_{w}$ may be lowered. This remark also applies to the apolar polyurethanes containing fluorine. However, the results of determination degrees polydispersity of molecular weights are rather correct and show that the values of $M_{w} / M_{n}$ for the tested polyurethanes after exposition increase, but the increase for the copolymers is slight, which confirms their very favorable resistance to the effect of physiologic salt solution.

SFE measurements provide additional information relating to the surface of the tested samples (Table 5).

\begin{tabular}{|c|c|c|c|c|c|}
\hline \multirow{4}{*}{$\begin{array}{l}\text { Sample } \\
\text { No. }\end{array}$} & \multicolumn{2}{|c|}{$\begin{array}{c}\text { Experimental values of contact angles } \Theta\left[{ }^{\circ}\right] \\
\text { Standard deviation }\end{array}$} & \multicolumn{3}{|c|}{$\begin{array}{l}\text { Parameters of SFE }\left[\mathrm{mJ} / \mathrm{m}^{2}\right] \\
\text { Standard deviation }\end{array}$} \\
\hline & \multicolumn{5}{|c|}{ before exposure/after exposure } \\
\hline & \multicolumn{2}{|c|}{ Model measuring fluids } & & & \\
\hline & $\mathrm{CH}_{2} \mathrm{I}_{2}$ & Water & $\gamma_{L}{ }^{u}$ & $\gamma_{L}{ }^{\rho}$ & $\gamma_{L}$ \\
\hline PU-1-E & $\begin{array}{l}33.27 / 30.74 \\
1.357 / 1.650\end{array}$ & $\begin{array}{l}79.79 / 76.69 \\
0.893 / 0.747\end{array}$ & $\begin{array}{c}39.50 / 40.46 \\
0.09 / 0.10\end{array}$ & $\begin{array}{l}3.58 / 4.73 \\
0.01 / 0.01 \\
\end{array}$ & $\begin{array}{c}43.08 / 45.19 \\
0.09 / 0.10\end{array}$ \\
\hline PU-2-E & $\begin{array}{l}60.99 / 58.93 \\
1.246 / 0.643\end{array}$ & $\begin{array}{l}91.45 / 90.10 \\
1.253 / 0.536\end{array}$ & $\begin{array}{c}25.54 / 26.87 \\
0.08 / 0.04\end{array}$ & $\begin{array}{l}2.77 / 3.05 \\
0.01 / 0.01\end{array}$ & $\begin{array}{c}28.31 / 29.92 \\
0.08 / 0.04\end{array}$ \\
\hline PU-3-K & $\begin{array}{l}34.14 / 32.10 \\
1.550 / 1.268\end{array}$ & $\begin{array}{l}81.24 / 80.42 \\
1.744 / 1.973\end{array}$ & $\begin{array}{l}39.33 / 39.23 \\
0.11 / 0.09\end{array}$ & $\begin{array}{l}3.71 / 3.90 \\
0.02 / 0.02\end{array}$ & $\begin{array}{c}43.04 / 43.13 \\
0.11 / 0.10\end{array}$ \\
\hline PU-4-K & $\begin{array}{l}35.35 / 35.26 \\
1.030 / 0.507\end{array}$ & $\begin{array}{l}84.20 / 83.48 \\
1.700 / 1.735\end{array}$ & $\begin{array}{l}40.28 / 40.21 \\
0.08 / 0.05\end{array}$ & $\begin{array}{l}1.72 / 1.93 \\
0.01 / 0.01 \\
\end{array}$ & $\begin{array}{c}42.00 / 42.14 \\
0.08 / 0.06\end{array}$ \\
\hline
\end{tabular}
They show that the polarity of the PU elastomers and

Table 5. Experimental values of contact angles, parameters of SFE as calculated by Owens-Wendt method for PU elastomers and poly(urethane-methacrylate) copolymers before and after exposure in physiologic salt solution 
a)

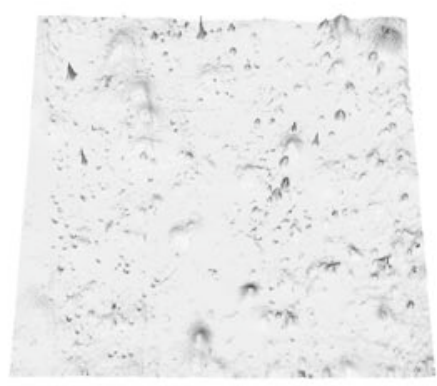

c)

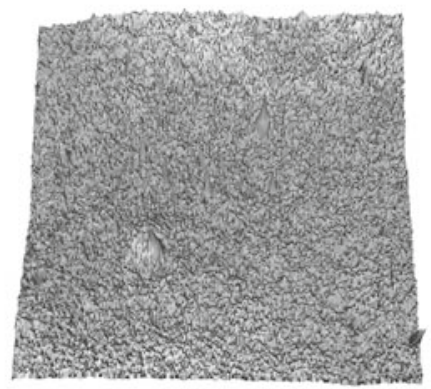

e)

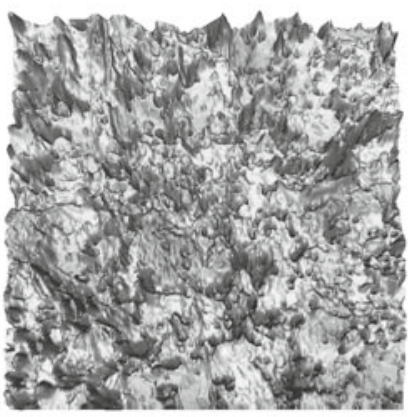

g)

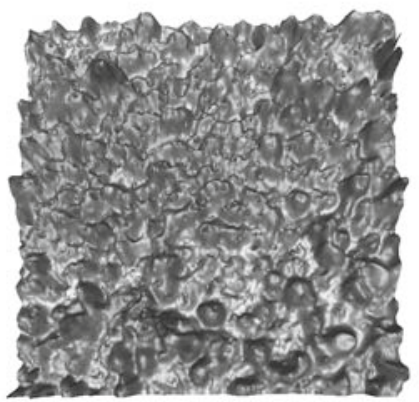

b)

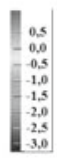

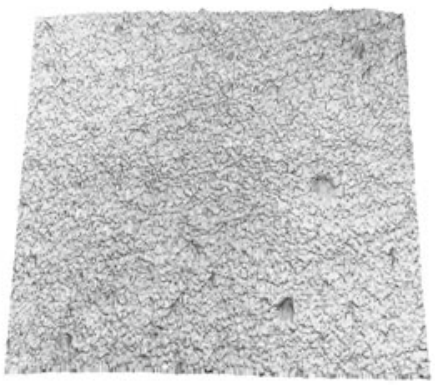

$\mid \begin{array}{r}0,5 \\ 0,0 \\ -0,5 \\ 1.0 \\ -1,5 \\ 2.0 \\ -2,5 \\ -3,0 \\ \hline\end{array}$

d)

-0.2
0.0
$-0,2$
0.4
-0.6
-0.8

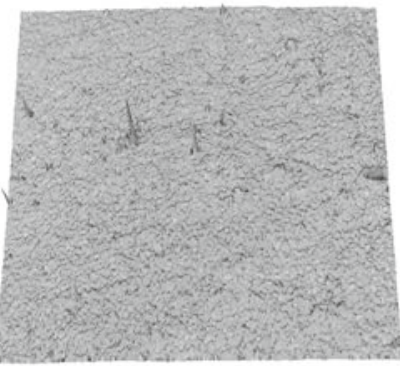

1,0
0,0
$-1,0$
$-2,0$

f)

1,0
$-0,0$
$-1,0$
$-2,0$
$-3,0$

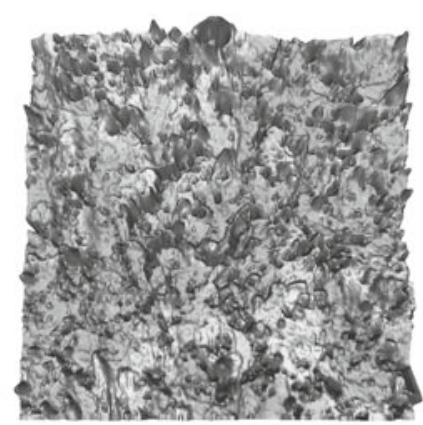

$\begin{array}{r}-2,0 \\ -1,0 \\ 0,0 \\ -1,0 \\ -2,0 \\ \hline\end{array}$

h)

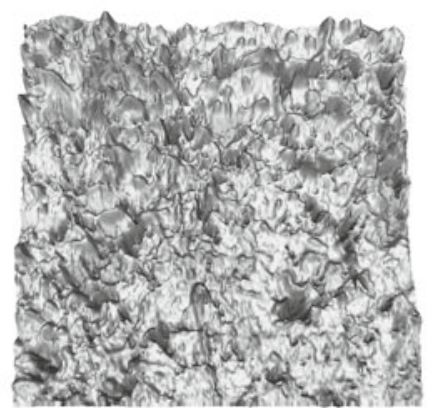

\begin{tabular}{|r|}
$\mid, 0$ \\
$-0,0$ \\
$-1,0$ \\
$-2,0$ \\
$-3,0$ \\
$-4,0$ \\
\hline
\end{tabular}

Figure 5. Confocal images of the elastomers PU-1-E (a, b), PU-2-E (c, d) and copolymers PU-3-K (e, f), PU-4-K (g, h), in physiologic salt solution, were taken for the objects $320 \times 320 \mu \mathrm{m}$ and with magnification $50 \times$ 
poly(urethane-methacrylate) copolymers is similar, and their value of the $S F E$ is $\gamma_{S}=42-43 \mathrm{~mJ} / \mathrm{m}^{2}$, in addition with a dominant contribution from dispersion interactions $\gamma_{S}^{d}(90 \%)$, than the polar $\gamma_{S}^{d}$ (below 10\%). However, PU containing fluorine is definitely more hydrophobic: $\gamma_{S}=28 \mathrm{~mJ} / \mathrm{m}^{2}$. This confirms the strong influence of fluorine on the change of the character of the polymer surface, described in our earlier work ${ }^{\mathbf{2 7}, 28}$. However, there is no doubt - in view of the precision of the performed measurements - that $S F E$ values of the surface of PU elastomer samples after incubation in physiologic salt solution grow about a few $m \mathrm{~J} / \mathrm{m}^{2}$, and of copolymers only to a little, although clearly marked degree. As expected, the increase of $\gamma_{s}^{p}$ component is relatively greater than the $\gamma_{S}^{d}$ component, although the dispersion influences in each of the analyzed cases make a much greater contribution to the $S F E$ of studied coatings. It can be concluded that the hydrolysis conditions are conducive to the formation of polar groups on the surface of polymer samples. Most likely, these groups are formed by hydrolysis of urethane bonds, always present in small quantities in PU urea bonds, as well as by limited hydrolysis of the ether bonds.

The hydrolysis of the above mentioned segments and bonds, has even a small effect on the morphology of the sample. On the first layer of polymer coating hydrolytic degradation takes place and with time, also within the interior of the sample. These changes can be imaged using a confocal microscope. The resulting images confirm the more diversified shape of the surfaces in the samples subjected to the hydrolytic degradation, but it is definitely more visible in the case of the samples of poly(urethane-methacrylate) copolymers, in spite of small changes in SFE. However, it must be noted that the surface morphology of these samples was also before degradation - as can be seen in Figure 5 - more diversified, and their surface is rougher, which is indicated by $R_{a}$ and $R_{z}$ parameters, determined by using the confocal microscope (Table 1 ). The values of these parameters for a given coating prepared from the given polymer after degradation is approximately 6 times higher, which can be explained as a result of grooving of the surface by rinsing of the hydrolysis products. The diverse morphology of PU coatings, and coatings derived from poly(urethane-methacrylate) copolymers is probably a result of the greater phase separation of generally polar segments derived from polyurethane and more hydrophobic polymethacrylic segments, than flexible polyol segments and and rigid urethane segments typical for PU elastomers. In addition, the information about possible changes in the structure and morphology of the studied samples can be obtained by analyzing their thermal resistance. The

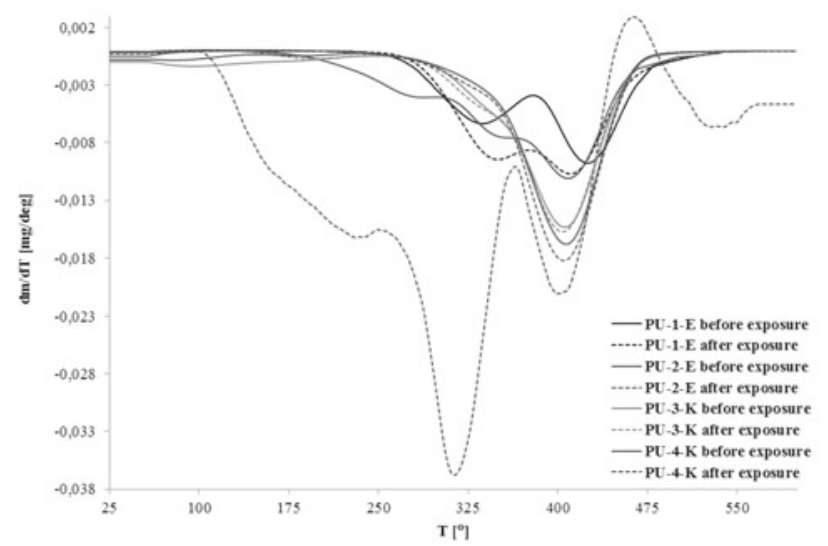

Figure 6. DTG thermograms for PU elastomers and poly-(urethane-methacrylate) copolymers before and after exposure in physiologic salt solution

TG and DTG thermograms for the samples before and after exposures were similar in nature, and only accurate quantitative analysis has revealed a small, but significant differences (Fig. 6). The results of these determinations are shown in Table 6.

The most complex thermal decomposition was observed for the PU-2-E fluorinated elastomer sample. It proceeded in three stages. In the first-stage $\left(\mathrm{T}=278^{\circ} \mathrm{C}\right)$ the polymer has already lost about $17 \%$ mass. In the second-stage degradation occurs quickly, while in the third-stage destruction is already very deep and probably includes not only the polar aromatic urethane segments, but also more stable ether segments. From this point, in the decomposition of PU-1-E elastomer only 2 stages can be identified, a very rapid weight loss with a deep rapid degradation in the range of $300-400^{\circ} \mathrm{C}$.

PU-2-E sample after exposure is less stable and its decomposition begins at $230^{\circ} \mathrm{C}$. Also at a slightly lower temperature, but with similar performance about $51 \%$ losses of mass - as in samples before exposure - there are II and III stages degradation of this sample. Thermal decomposition of PU-1-E sample after exposure already occurs more quickly, i.e. with the greater loss of the mass, but the second-stage (for this sample it is indeed the first-stage) occurrs at a higher temperature by $10 \mathrm{deg}$ $\left(344^{\circ} \mathrm{C}\right)$, and the third-stage (for this sample it is also the second-stage) similarly has a significantly higher loss of the mass (about $50 \%$ ), but it is noted at $407^{\circ} \mathrm{C}$. The above analysis shows indirectly both significant differences in the mechanisms of the degradation of PU-1-E and PU-2-E samples, but also subtle, yet detectable changes in resistance of the elastomers after exposure in physiologic salt solution, which in turn proves the occurrence of certain structural changes, in addition differences in the course of exothermic effects recorded on the DTA

Table 6. Thermal stability of the PU elastomers and poly(urethane-methacrylate) copolymers before and after exposure in physiologic salt solution

\begin{tabular}{|c|c|c|c|c|c|c|c|c|c|c|c|c|c|c|}
\hline \multirow{3}{*}{$\begin{array}{l}\text { Sample } \\
\text { No. }\end{array}$} & \multicolumn{4}{|c|}{ I stage degradation } & \multicolumn{4}{|c|}{ II stage degradation } & \multicolumn{4}{|c|}{ III stage degradation } & \multirow{2}{*}{\multicolumn{2}{|c|}{$\begin{array}{c}\text { Summary mass loss in } \\
\mathrm{T}=600^{\circ} \mathrm{C} \\
(\%)\end{array}$}} \\
\hline & \multicolumn{2}{|c|}{$\begin{array}{c}\text { before } \\
\text { exposure }\end{array}$} & \multicolumn{2}{|c|}{$\begin{array}{c}\text { after } \\
\text { exposure }\end{array}$} & \multicolumn{2}{|c|}{$\begin{array}{c}\text { before } \\
\text { exposure }\end{array}$} & \multicolumn{2}{|c|}{$\begin{array}{c}\text { after } \\
\text { exposure }\end{array}$} & \multicolumn{2}{|c|}{$\begin{array}{c}\text { before } \\
\text { exposure }\end{array}$} & \multicolumn{2}{|c|}{$\begin{array}{c}\text { after } \\
\text { exposure }\end{array}$} & & \\
\hline & $\begin{array}{l}\text { Mass } \\
\text { loss } \\
{[\%]}\end{array}$ & $\begin{array}{c}\mathrm{T} \\
{\left[{ }^{\circ} \mathrm{C}\right]}\end{array}$ & $\begin{array}{l}\text { Mass } \\
\text { loss } \\
{[\%]}\end{array}$ & $\begin{array}{c}\mathrm{T} \\
{\left[{ }^{\circ} \mathrm{C}\right]}\end{array}$ & $\begin{array}{l}\text { Mass } \\
\text { loss } \\
{[\%]}\end{array}$ & $\begin{array}{c}\mathrm{T} \\
{\left[{ }^{\circ} \mathrm{C}\right]}\end{array}$ & $\begin{array}{l}\text { Mass } \\
\text { loss } \\
{[\%]}\end{array}$ & $\begin{array}{c}\mathrm{T} \\
{\left[{ }^{\circ} \mathrm{C}\right]}\end{array}$ & $\begin{array}{l}\text { Mass } \\
\text { loss } \\
{[\%]}\end{array}$ & $\begin{array}{c}\mathrm{T} \\
{\left[{ }^{\circ} \mathrm{C}\right]}\end{array}$ & $\begin{array}{l}\text { Mass } \\
\text { loss } \\
{[\%]}\end{array}$ & $\begin{array}{c}\mathrm{T} \\
{\left[{ }^{\circ} \mathrm{C}\right]}\end{array}$ & $\begin{array}{l}\text { before } \\
\text { exposure }\end{array}$ & $\begin{array}{l}\text { after } \\
\text { exposure }\end{array}$ \\
\hline PU-1-E & - & - & - & - & 32.22 & 333 & 40.99 & 344 & 49.70 & 422 & 52.04 & 407 & 87.92 & 93.03 \\
\hline PU-2-E & 16.65 & 278 & 16.74 & 230 & 51.36 & 336 & 51.37 & 313 & 51.36 & 404 & 51,37 & 398 & 97.44 & 98.32 \\
\hline PU-3-K & - & - & - & - & 15.25 & 329 & 16.08 & 327 & 81.20 & 406 & 80.44 & 404 & 96.45 & 96.52 \\
\hline PU-4-K & - & - & - & - & - & - & - & - & 95.29 & 409 & 95.30 & 408 & 95.29 & 95.30 \\
\hline
\end{tabular}


thermograms, in the range of registered degradation temperatures, evidenced by the changes in the structure which are difficult to detect such low inherently sensitive NMR method. From an analysis of the TG and DTG thermograms of poly(urethane-methacrylate) copolymer samples it results that the thermal decomposition occurrs definitely differently from PU elastomers, i.e. in one (PU-4-K) or in two (PU-3-K) clearly and explicitly registered stages, and there is practically no difference in the resistance to the thermal degradation of the samples before and after exposure in physiologic salt solution. It is very beneficial for potential applications of these copolymers as biomaterials, because it indicates about the structural stability of these polymers during their exposure to the conditions that may cause the effects of hydrolytic degradation.

DSC thermograms for the samples before and after exposures were similar in nature, which is reflected by

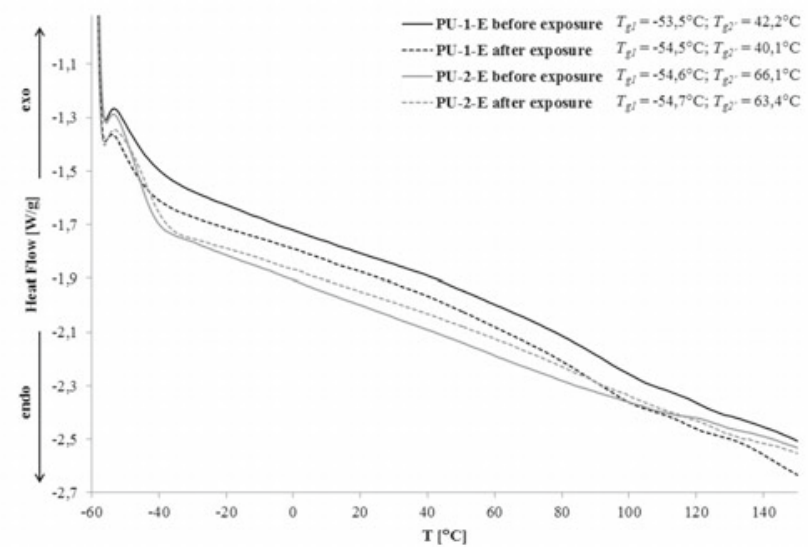

Figure 7. DSC thermograms for PU elastomers before and after exposure in physiologic salt solution

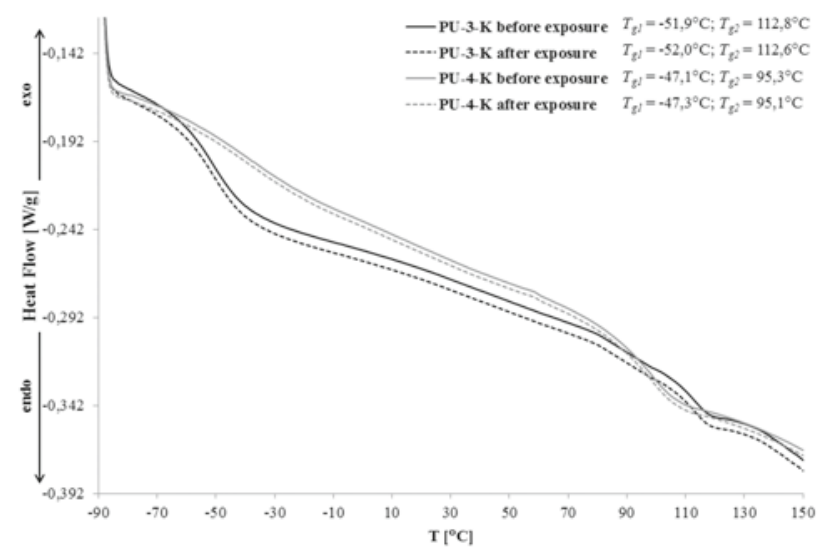

Figure 8. DSC thermograms for poly(urethane-methacrylate) copolymers before and after exposure in physiologic salt solution

virtually unchanged glass transition temperature values for positive and negative values Figure 7 and 8 . As shown in Figure 7, the $T_{g 1}$ of the flexible polyol segments present in PU-1-E and PU-2-E elastomers are observed at -54 and $-55^{\circ} \mathrm{C}$, respectively. The $T_{g 2}$, of the rigid urethane segments is observed at 42 and $66^{\circ} \mathrm{C}$, respectively. Furthermore, in the case of tri-block copolymers (Fig. 8) the DSC method analysis indicated a limited miscibility of phases containing rigid and flexible segments (forming the chain of the polymers under synthesis): two separate areas were present, to which distinct ranges of glass transition temperatures $\left(T_{g}\right)$ were assigned: $T_{g 1}=-47--52^{\circ} \mathrm{C}$ (corresponding to transitions in the flexible segments) and $T_{g 2}=95-113^{\circ} \mathrm{C}$ (characteristic for phase transitions occurring within the rigid PMMA segments introduced into the PU macroinitiator chain).

\section{CONCLUSIONS}

The performed examinations confirm the described in the literature, good resistance to hydrolysis of PU elastomer synthesized with MDI, PTMO and BD. For this reason, coating made from PU elastomers is applied as special protective coatings to the materials of the natural origin and as biomaterials. However, they are definitely polar coatings with the $S F E$ value above $40 \mathrm{~mJ} / \mathrm{m}^{2}$. Replacing part of hydrogen atoms by fluorine atoms by using as an efficient chains extension of urethane-isocyanate prepolymers TFBD in place of BD, causes substantial reduction of the polarity $\left(S F E<30 \mathrm{~mJ} / \mathrm{m}^{2}\right)$, but at the same time the morphology of the sample surface becomes more diverse, the roughness of the coating grows, which may be disadvantageous for the applications of this type of PU (here we omit the issues of the possible harmful effects of fluoride on the human body, which wasn't the subject of our discussion). The applied research methods: gel permeation chromatography, confocal microscopy and thermogravimetric analysis allowed to demonstrate significant differences in the resistance to hydrolysis in the physiologic salt solution of these polymers, although the changes in their chemical structure are slight: the change in the weight of the samples during storage in the physiologic salt solution didn't exceed $1 \%$, and water absorption $-2.5 \%$. This kind of hydrolysis probably happens in the most vulnerable on structural changes places of polyurethanes, even though the initial structure of macromolecules and the segmented construction of PU can be considered to be generally stable, due to the structural and morphology analysis carried out by NMR and DSC methods.

On the above background, poly(urethane-methacrylate) copolymers as new materials synthesized by ARGET ATRP method in the presence of limited amount of air allowing to control the size and polydispersity molecular weight of the polymer - create potential options for use as biomaterials with a slightly less polarity than PU elastomers. Here, there are great opportunities for further structural changes. Replacement of the urethane segments by more hydrophobic methacrylic segments contributes to an increase in the resistance to the hydrolysis of such block copolymers. The surface morphology of these materials is required in further research. Meanwhile, the confocal microscopy method demonstrated that it is highly variable, which has a large influence to the quality of biomaterial, because in the places of the inequality or structural dislocation, and faults of the phases built from the segments of different polarity the degradation processes can be initiated, causing pathological changes in the organ tissues being in contact with these areas.

\section{ACKNOWLEDGMENT}

The scientific work is cofinancing with resources of European Union, in frames of European Social Fund, 
and project Podkarpacki scholarship fund for doctoral students realized by Podkarpackie Province - Marshall office of the Podkarpacki Province in Rzeszów in frames of Operating Programme the Human Capital in years 2007-2013.

The authors wish to thank Mr Roven Lenz, Applikation und Service Director Marketing and Sales, NANOFOCUS AG, and Mr Ireneusz Niemiec from NANOFOCUS Poland for realization of measurements with the use of confocal microscope.

\section{LITERATURE CITED}

1. Król, P. (2008). Linear Polyurethans. Synthesis methods, chemical structures, properties and applications. Boston, USA: NV. Leiden, The Netherlands Leiden.

2. Yang, Q. \& Ye, L. (2013). Mechanical and thermal properties of polyurethane elastomers synthesized with toluene diisocyanate trimer. J. Polym. Sci. Part B: Polym. Phys. 52, 138-154. DOI: 10.1080/00222348.2012.695631.

3. Ahmad, N., Khan, M.B., Ma, X., Ul-Haq, N. \& IhtashamUr-Rehman. (2012). Dynamic mechanical characterization of the crosslinked and chain-extended HTPB based polyurethanes. Polym. Compos. 20, 683-692.

4. Liu, C., Zhang, Z., Liu, K.L., Ni, X. \& Li, J. (2013). Biodegradable thermogelling poly(ester urethane)s consisting of poly(1,4-butylene adipate), poly(ethylene glycol), and poly(propylene glycol). Soft Matter. 9, 787-794. DOI: 10.1039/ C2SM26719E.

5. Yamamaoto, K., Kimura, T., Nam, K., Funamoto, S., Ito, Y., Shiba, K., Katoh, A., Shimizu, S., Kurita, K., Hihami, T., Masuzawa, T. \& Kishida, A. (2011). Synthetic polymer-tissue adhesion using an ultrasonic scalpel. Surg. Endos. Other Unterventional Techniques 25, 1270-1275. DOI: 10.1007/s00464010-1357-7.

6. Ma, Z., Hong, Y., Nelson, D.M., Pichamuthu, J.E., Leeson, C.E. \& Wagner, W.R. (2011). Biodegradable polyurethane ureas with variable polyester or polycarbonate soft segments: Effects of crystallinity, molecular weight, and composition on mechanical properties. Biomacromol. 12, 3265-3264. DOI: 10.1021/bm2007168.

7. Page, J.M., Prieto, E.M., Dumas, J.E., Zienkiewicz, K.J., Wenke, J.C., Brown-Baer, P. \& Guelcher, S.A. (2012). Biocompatibility and chemical reaction kinetics of injectable, settable polyurethane/allograft bone biocomposites. Acta Biomater. 8, 4405-4416. DOI: dx.doi.org/10.1016/j.actbio.2012.07.037.

8. Gogolewski, S. (1989). Selected topics in biomedical polyurethanes. A review. Coll. Polym. Sci. 267, 757-185. DOI: 10.1007/BF01410115.

9. Król, P. \& Byczyński, Ł. (2008). Influence of chemical structure on the values of free surface energy oft he coatings made of poly(urethane-siloxane) copolymers. Polimery 53, 808-816. [in Polish].

10. Seyedmehdi, S.A., Zhang, H. \& Zhu, J. (2013). Fabrication of superhydrophobic coatings based on nanoparticles and fluoropolyurethane. J. Appl. Polym. Sci. 128, 4136-4140. DOI: 10.1002/app.38418.

11. Król, B., Król, P., Pielichowska, K. \& Pikus, S. (2011). Comparison of phase structures and surface free energy values for the coatings synthesised from linear polyurethanes and from waterborne polyurethane cationomers. Coll. Polym. Sci. 289, 757-1767. DOI: 10.1007/s00396-011-2515-8.

12. Wang, L.F. \& Wie, Y.H. (2005). Effect of soft segment length on properties of fluorinated polyurethanes. Coll. Surf. B: Biointerf. 41, 249-255. DOI: dx.doi.org/10.1016/j. colsurfb.2004.12.014.

13. Pereira, I.H.L., Ayres, E., Patricio, P.S., Góes, A.M., Gomide, V.S., Junior, E.P. \& Oréfice, R.L. (2010). Photopolymerizable and injectable polyurethanes for biomedical applications:
Synthesis and biocompatibility. Acta Biomater. 6, 3056-3066. DOI: dx.doi.org/10.1016/j.actbio.2010.02.036.

14. Król, P. \& Chmielarz, P. (2013). Synthesis of PMMA$b$-PU-b-PMMA tri-block copolymers through ARGET ATRP in the presence of air. Express Polym. Lett. 7, 249-260. DOI: 10.3144/expresspolymlett.2013.23.

15. Sharifpoor, S., Labow, R. \& Santerre, S.P.J. (2009). Synthesis and characterization of degradable polar hydrophobic ionic polyurethane scaffolds for vascular tissue engineering applications. Biomacromol. 10, 2729-2739. DOI: 10.1021/bm9004194.

16. Król, P. \& Chmielarz, P. (2011). Controlled radical polymerization (CRP) methods in the synthesis of polyurethane copolymers. Polimery (in Polish) 56, 530-540.

17. Verma, H. \& Tharanikkarasu, K. (2008). Novel telechelic 2-methyl-2-bromopropionate terminated polyurethane macroinitiator for the synthesis of ABA type tri-block copolymers through atom transfer radical polymerization of methyl methacrylate. Polym. J. 40, 867-874. DOI: 10.1295/polymj.PJ2007236.

18. Verma, H. \& Tharanikkarasu, K. (2010). Atom transfer radical polymerization of methyl methacrylate using telechelic tribromo terminated polyurethane macroinitiator. $J$. Macromol. Sci. Part A: Pure Appl. Chem. 47, 407-415. DOI: 10.1080/10601321003699671.

19. Szelest-Lewandowska, A., Masiulanis, B., Klocke, A., Glasmacher, B. \& Glasmacher, B. (2003). Synthesis, physical properties and preliminary investigation of hemocompatibility of polyurethanes from aliphatic resources with castor oil participation. J. Biomater. Appl. 17, 221-236. DOI: 10.1177/0885328203017003480.

20. Mondal, S. \& Martin, D. (2012). Hydrolytic degradation of segmented polyurethane copolymers for biomedical applications. Polym. Degrad. Stab. 97, 1553-1561. DOI: 10.1016/j. polymdegradstab.2012.04.008.

21. Stodolak, E., Paluszkiewicz, C., Błażewicz, M. \& Kotela, I. (2009). In vitro biofilms formation on polymer matrix composites. J. Mol. Struct. 924, 562-566. DOI: dx.doi.org/10.1016/j. molstruc.2009.01.017.

22. Król, P. \& Chmielarz, P. (2014). Synthesis of PMMA$b$-PU-b-PMMA tri-block copolymers through ARGET ATRP of methyl methacrylate using tetraphenylethane-urethane macroiniferter in the presence of air. Polimery. (in Polish) 59, 279-292. DOI: dx.doi.org/10.14314/polimery.2014.279.

23. Król, P. \& Pilch-Pitera, B. (2003). A study on the synthesis of urethane oligomers. Eur. Polym. J. 39, 1229-1241. DOI: dx.doi.org/10.1016/S0014-3057(02)00375-0.

24. Owens, D.K., Wendt, R.C. (1969). Estimation of the surface free energy of polymers. J. Appl. Polymer Sci. 13, 1741-1747. DOI: 10.1002/app.1969.070130815.

25. Laib, S., Krieg, A., Rankl, M. \& Seeger, S. (2006). Supercritical angle fluorescence biosensor for the detection of molecular interactions on cellulose-modified glass surfaces. Appl. Surf. Sci. 252, 7788-7793. DOI: dx.doi.org/10.1016/j. apsusc.2005.09.017.

26. Zisman, W.A. (1964). Relation of the equilibrium contact angle to liquid and solid constitution. (Eds.) In F.M. Fowkes. Contact Angle, Wettability, and Adhesion. (pp. 1-51). Washington: American Chemical Society. DOI: 10.1021/ba-1964-0043.ch001.

27. Król, P., Lechowicz, J.B. \& Król, B. (2013). Modelling the surface free energy parameters of polyurethane coats part 1. Solvent-based coats obtained from linear polyurethane elastomers. Coll. Polym. Sci. 291, 1031-1047. DOI: 10.1007/ s00396-012-2826-4.

28. Król, P., Lechowicz, J.B. \& Król, B. (2013). Modelling the surface free energy parameters of polyurethane coats - part 2. Waterborne coats obtained from cationomer polyurethanes. Coll. Polym. Sci., sent to the Editor. 